\title{
Modulare externe Reposition und Fixation
}

Dankward Höntzsch, Alberto Fernandez

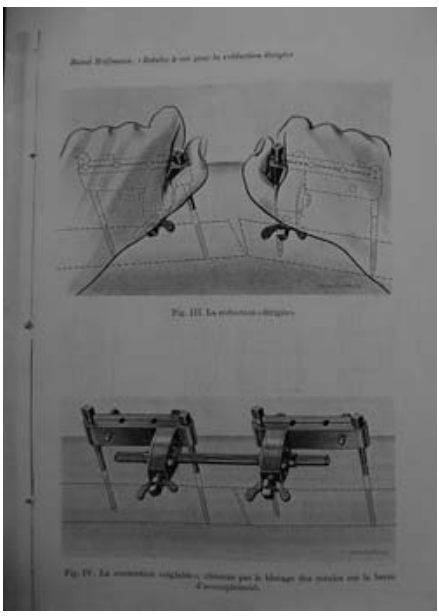

- Abb. 1 Modulartechnik von Raoul Hoffmann 1940/1959 [1].

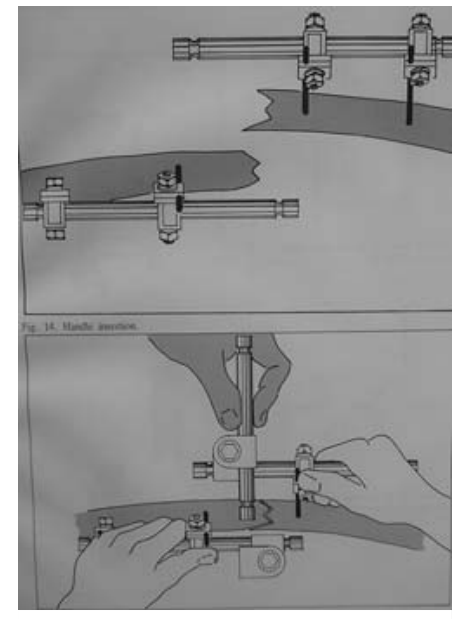

- Abb. 2 Moduletechnik von Alberto Fernandez, Montevideo 1998 [3].
Die modulare externe Reposition und Fixation kann an allen schaft- und gelenknahen Frakturen und allen Luxationen und mit allen modularen Rohr/Stab/Backen/PinSystemen verschiedener Hersteller durchgeführt werden, wenn ein externer Fixateur angezeigt ist. Die modulare Reposition und Fixation war schon von Raoul Hoffman in den ersten Fixateuren erstmals 1938! [1], dann mehrmals bis 1959 [2] publiziert und „eingebaut" gewesen ( $\triangleright$ Abb. 1) und ist von Alberto Fernandez 1989 [3] für das A0-Rohrsystem entwickelt worden ( $\bullet$ Abb. 2). Diese Methode ist heute Standard [4]. Hier sollen am Beispiel einer Tibiafraktur die einzelnen Schritte in Erinnerung gerufen werden.( $\mathbf{A b b}$. $\mathbf{3}$ ). Das Poster (Abb. Gegenseite) soll alle mögliche Montagen an einem Skelett zeigen. Sie können es sich heraustrennen.

\section{Literatur}

[1] Hoffmann R. Rotules à os pour la réduction dirigée, non sanglante, des fractures (ostéotaxis). Congress Suisse de Chirurgie, 1938 et Helv Med Acta 1938; 6: 844-850

[2] Hoffmann R. Osteotaxis. Perkutane Knochenfixierung. Stuttgart: Enke; 1959

[3] Fernandez A. Modular external Fixation with the AO tubular System. Montevideo: Eigenverlag; 1989

[4] Buckley RF, Moran CG, Apivatthakakul T, eds. AO Principles of Fracture Management. 3rd ed. Stuttgart, New York: Thieme; 2017

[5] Höntzsch D Modularer Fixateur Externe. OP Journal 2008; 24: 4-9. doi:10.1055/s-2008-1077282

Korrespondenzadresse

Prof. Dr. Dankward Höntzsch

Tübingen, hoentzsch@t-online.de

\section{Alberto Fernandez}

Montevideo, Uruguay

\section{Bibliografie}

DOI https://doi.org/10.1055/a-1144-7853

OP-JOURNAL 2020; 36: 164-165 @ Georg Thieme Verlag KG Stuttgart · New York ISSN 0178-1715
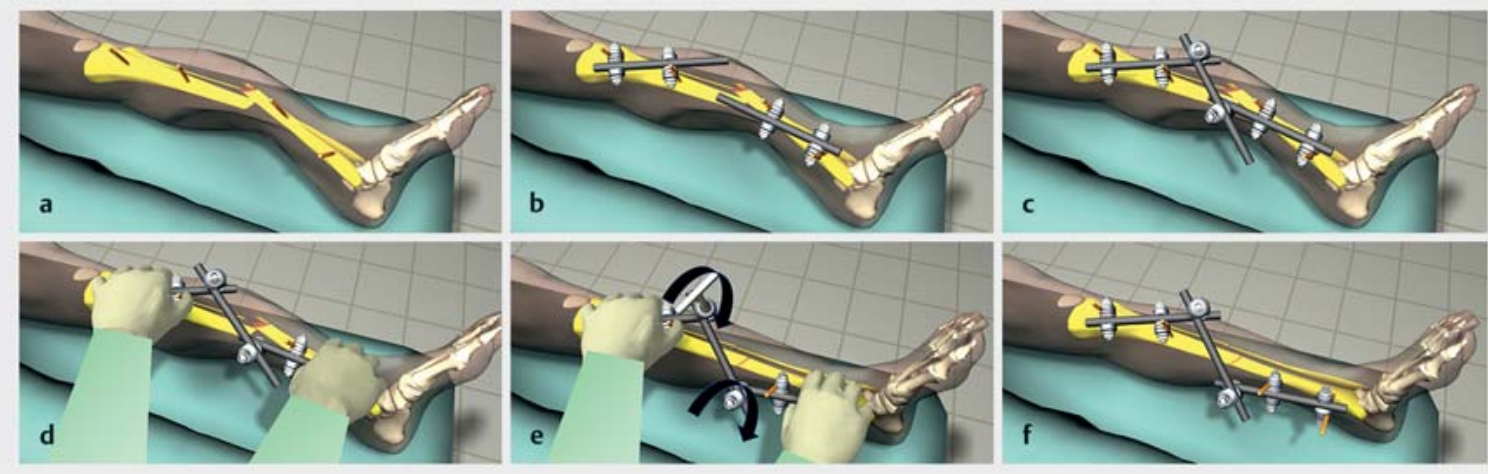

- Abb. 3 Ablauf der Ex-Fix-Modulartechnik am Beispiel einer Tibiaschaftfraktur links. a Vor der endgültigen Reposition je 2 Schanz'sche Schrauben ins prox. und dist. Hauptfragment. b Für jedes Hauptfragment einen Teilrahmen. Wichtig: alle Muttern fest ziehen! c Vorlegen eines dritten modularen Rohres/Rods mit Rohr-zu-Rohr-Backen (egal welcher Generation) dann vor Anziehen: $\mathbf{d}$ Reposition mit den Teilrahmen als Hebel. e Wenn Reposition gelungen und geprüft ist: Zudrehen der Rohr-zu-Rohr-Backen. Dieses Manöver kann nach Öffnen beider Rohr-zu-Rohr-Backen wiederholt werden, bis die Reposition gut gelungen ist. $f$ Modulare Montage. 


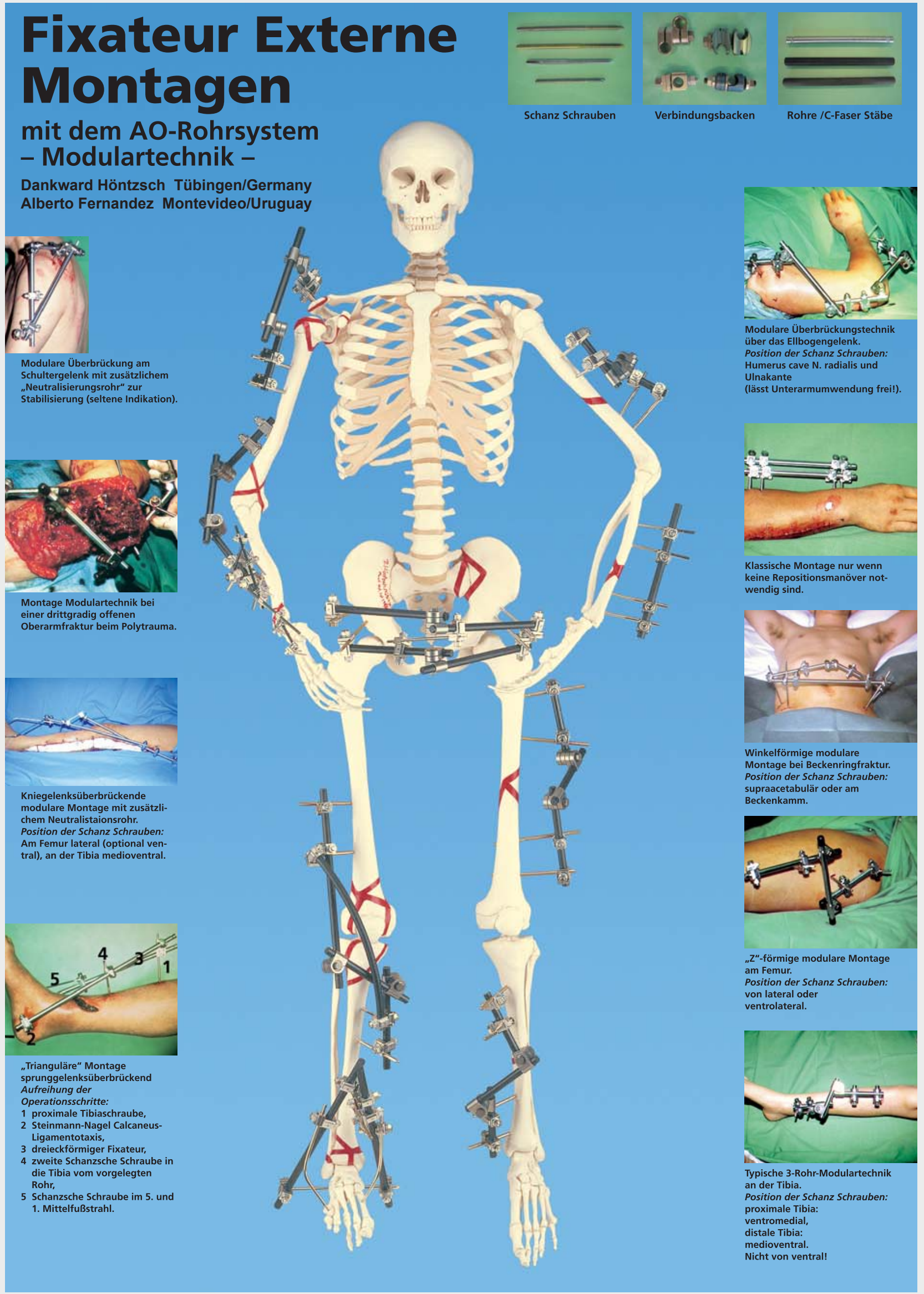

